assessment in the treatment of cardiac hypertrophy(CATH) study. J. Hypertens. 2002. 20(11). P. 2293-2300.

4. Easthope S.E., Jarvis B. Candesartan cilexetil: an update of its use in essential hypertension. Drugs. 2002. 62(8). P. 1253-1287.

DOI https://doi.org/10.30525/978-9934-26-113-8-8

\title{
THE ROLE OF ERCP IN THE TREATMENT OF BILIARY FISTULA
}

\author{
Moskaliuk O. P. \\ Candidate of Medical Sciences, \\ Associate Professor at the Department of Surgery № 2 \\ Bukovinian State Medical University \\ Shkvarkovskyj I. V. \\ Doctor of Medical Sciences, \\ Head of the Department of Surgery № 2 \\ Bukovinian State Medical University \\ Chernivtsi Ukraine
}

Patients with gallstone disease make up from $10 \%$ to $15 \%$ of the adult population and about $30 \%$ of them will be operated [1,2]. Cholecystectomy is one of the most common surgeries in the world. Laparoscopic cholecystectomy is accompanied by an increase in the frequency of early biliary complications, which is noticed by most researchers [3,4]. Bile leakage as a result of minor damage to the bile ducts, is most often the result of failure of the stump of the cystic duct, damage to the aberrant and subvesical ducts.

The most common cause of biliary fistula is biliary hypertension due to residual choledocholithiasis [4]. Recent studies indicate that bile fistulas complicate approximately $1.2-2 \%$ of laparoscopic cholecystectomies. It is important that the percentage of early postoperative complications directly depends on the full preoperative diagnosis of choledocholithiasis and its correction.

So the main purpose of our research is to analyze the endoscopic treatment of patients with biliary fistulas after cholecystectomy.

Materials and methods. The results of endoscopic treatment of 29 patients with biliary fistulas that occurred after cholecystectomy were analyzed. All patients have been treated at the Center for Endoscopic Surgery of Bukovinian State Medical University since 2016 to 2021 . There were 17 women (58.6\%) and 12 men (42.4\%). The mean age was $60.8 \pm 12.46$ years (36 to 84 years). Cholecystectomy in the classical version was performed in 13 (44.8\%) 32 
patients of the total number of operations; standard 4-port laparoscopic cholecystectomy was performed in $10(55.2 \%)$ patients.

All patients underwent endoscopic retrograde holangiopancreatography (ERCP). The main way to access the common bile duct was its cannulation using a standard papillotome and the introduction of a guidewire. The most common cause was the failure of the cystic duct - $16(55.2 \%)$ patients. In second place - damage to the duct of the gallbladder bed - 7 (20.7\%) cases. The cause of biliary fistula was biliary hypertension, which arose on the background of residual choledocholithiasis in $22(75.9 \%)$ patients. Endoscopic papillosphincterotomy was performed in all cases to restore free passage of bile into the duodenum. Balloon lithoextraction was performed in $16(55.2 \%)$ patients, in another $5(17.2 \%)$ patients we used basket lithoextraction. In $9(31.0 \%)$ patients for successful lithoextraction had to perform balloon dilatation of the sphincter of Oddi and the terminal part of common bile duct. Another $8(27.6 \%)$ patients underwent endobiliary drainage with a polypropylene stent with a diameter of $10 \mathrm{Fr}$.

Ensuring endobiliary decompression in all cases of type A bile fistula resulted in cessation or a sharp decrease in the day after ERCP and fistula healing within a few days. The phenomena of mechanical jaundice were also eliminated - the average level of bilirubin on the 2nd day after surgery was $26.3 \pm 4.18 \mu \mathrm{mol} / \mathrm{l}$, compared with the preoperative level $(63.2 \pm 11.61 \mu \mathrm{mol} / \mathrm{l})$.

Unfortunately, endoscopic methods are not effective in detecting choledochal lesions and type D bile fistula (3 (10.3\%) patients). These patients required difficult reconstructive surgeries.

Thus, ERCP is a highly effective method of treatment of biliary fistulas, which allows to assess the integrity of the main bile ducts, the presence of biliary hypertension and residual stones. ERCP identifies the site of bile leakage, and sphincterotomy, dilatation, lithoextraction, or endobiliary drainage directs bile flow to the duodenum and promotes fistula healing.

\section{References:}

1. Saito H., Kakuma T., Kadono Y., Urata A., Kamikawa K., Imamura H., Tada S. Increased risk and severity of ERCP-related complications associated with asymptomatic common bile duct stones. Endosc Int Open. 2017 Sep;5(9):P. 809-817.

2. Ze-Hui Lv, Kou D., Guo S. Three-hour post-ERCP amylase level: a useful indicator for early prediction of post-ERCP pancreatitis. BMC Gastroenterol. 2020.118. P. 21-28.

3.Насташенко И.Л. Транспапиллярные вмешательства у больных c неопухолевой билиарной обструкцией. Хірургія України. 2016. № 2. С. 56-60.

4. Подолужный В.И. Осложнения желчнокаменной болезни. Фундаментальная и клиническая медищина. 2017. №1. С. 102-114. 